8. Respiratory rate

9. Systolic blood pressure

10. GCS* E-score

11. GCS* M-score

12. GCS* V-score

*Glasgow Coma Scale score

When it is necessary to make a choice, a help screen shows automatically the possibilities. Some help screens bring the users to the exact injuries by walking them through a decision tree.

After finishing the input, three screens will be shown:

1) All the data for the patient with the possibility to change one or more items.

2) AlS-codes; and

3) Calculated trauma scores, Glasgow Coma Scale scores, TRTS, RTS, ISS, TRISS, and ASCOT. There will be a demonstration of this program for interested colleagues.

\title{
107.
}

\section{Forensic Expertise of Victims of an Electric Power Station Incident}

M. Grozeva, V. Popzakharieva, Ts. Boshnakova, V. Nankova,

Kh. Elensky, T. Todorov, Al. Minchev, E. Buchvarov

Higher Medical Institute, Stara Zagora, Bulgaria

On 10 October 1994 at 10:51 hours, a $2,000 \mathrm{~m}^{3}$ drainage condensation tank split at a seam. The $5 \mathrm{~m}$ high wave (temperature $=80-90^{\circ} \mathrm{C}$ ) swept over two shops and a pedestrian crossing. One of them was completely destroyed. There were 25 victims: 21 died: 17 males and 4 females, aged $20-60$ years. Of these victims, a man and a woman just were passing by, while all the others were at their place of work. All victims were taken by bus to the nearest hospital where they were given first aid. Reanimation ambulances took the victims to the regional hospital where three were hospitalized. The rest were transported to specialized clinics for burns: 12 to Sofia and three to Plovdiv. Six of the victims with $100 \%$ burns, both inhaled and ingested hot water and, with mechanical traumas localized in the head, thorax, and spinal column, died at the site of the accident. Five victims with $97-100 \%$ burns died within three days of the incident, and the rest who had $70-80 \%$ burns lived up to 21 days. All of them had inhaled and ingested hot water and had a severe thermal shock.

Investigation of changes in the different groups, studied by optical microscopy, has enriched data about the early stages of shock. In the group of victims who died within 21 days, evidence of proliferative shock stage was found. Those who survived the accident ( $30 \%$ burns) were categorized as having suffered a battery with health disturbance and temporally endangering of life in accordance with the Bulgarian Penal Code. From an organizational and forensic point of view, the transportation of victims who had inhaled and ingested hot water to the specialized clinics was inexpedient and made the treatment unduly expensive. 